\title{
COUPLING THE DISCRETE ELEMENT METHOD WITH THE FINITE ELEMENT METHOD TO SIMULATE ROCKFALL IMPACT EXPERIMENTS
}

\author{
Klaus B. Sautter*†, Helene Hofmann", Corinna Wendeler ${ }^{\S}$, Miguel Angel \\ Celigueta $^{\ddagger}$, Philipp Bucher ${ }^{\dagger}$, Kai-Uwe Bletzinger ${ }^{\dagger}$ and Roland Wüchner ${ }^{\dagger, \ddagger}$ \\ ${ }^{\dagger}$ Technical University of Munich (TUM), Chair of Structural Analysis \\ Arcisstr. 21, D-80333 Mnchen, Germany \\ e-mail: klaus.sautter@tum.de, web page: www.st.bgu.tum.de \\ ¥Centre Internacional de Mètodes Numèrics en Enginyeria (CIMNE) \\ Campus Nord UPC, 08034 Barcelona, Spain \\ " Geobrugg AG, Aachstr. 11, Romanshorn 8590, Switzerland \\ $\S$ Appenzell Ausserrhoden, Department of Construction and Economics, Civil Engineering \\ Office, Hydraulic Engineering, Kasernenstr. 17A, Herisau 9102, Switzerland
}

Key words: DEM, FEM, Impact, Multi-Physics Problems, Partitioned Coupled Simulation, Natural Hazards, Rockfall, Flexible Tension Structures, Mapping, Interface

\begin{abstract}
To numerically simulate rockfall impact on flexible protection structures two different numerical methods are coupled within the open-source multi-physics code KRATOS. The impacting object is modeled with the help of a cluster of spherical discrete elements and its movement and contact forces are simulated using the Discrete Element Method (DEM). To realize a partitioned coupling simulation the contact forces are subsequently transferred to the light-weight protection structure which is analyzed and simulated using the Finite Element Method (FEM). To allow a stable simulation even in the case of large contact forces and/or large time steps a strong coupling GaussSeidel algorithm is presented. Subsequently the applicability of the method is shown by calculating experiments and finally the inclusion of digital terrain data is demonstrated.
\end{abstract}

\section{INTRODUCTION}

Rockfall events can cause serious damage to populated areas and infrastructure located in mountainous regions. To properly secure these vulnerable zones a variety of different protection structures are used. They can be divided in two main groups: active and passive constructions. Active protection structures represent near-surface steel nets and 
Klaus B. Sautter et al.

prevent the detachment of individual rocks. Passive protection structures do not prevent the rockfall event but either catch the falling rock or guide it to a safe zone. While active structures are easier to dimension as there is no dynamic load case to consider, the analysis of passive protection structures is demanding and subject of this work. Similar to the assessment of the influence of other natural hazards on structures, like wind $[21,23]$ and debris-flow $[18,19]$ the impact loads from rockfall events are highly non-linear because the structural response itself influences the load in return. First investigated by [17], many other works have since been done on it. A special element to numerically model the heavily used ring-elements has been developed by [24] while others like [20, 25, 26, 27] have been investigating the numerical simulation of rockfall impacts and the respective structural response. Recently [13] discussed the combination of DEM and FEM to model the impact scenario on the bases of the work of $[10,11]$. This allows to use two standalone solvers to be combined in a co-simulation environment and use the strengths of the respective participants. While the DEM is used to model and simulate the impacting object and its contact forces with the structure, the FEM is employed to analyze the respective struetural response. The highly non-linear nature of this impact scenario calls for an effective handling of the interface and the appropriate transfer and mapping of state variables. [12] has employed this strategy to simulate rockfall impact experiments

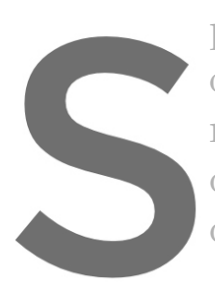
performed by the Swiss company Geobrugg of the aforementioned revision of the two pub ic data into the simulaticin can support a thoro The structure of the pro
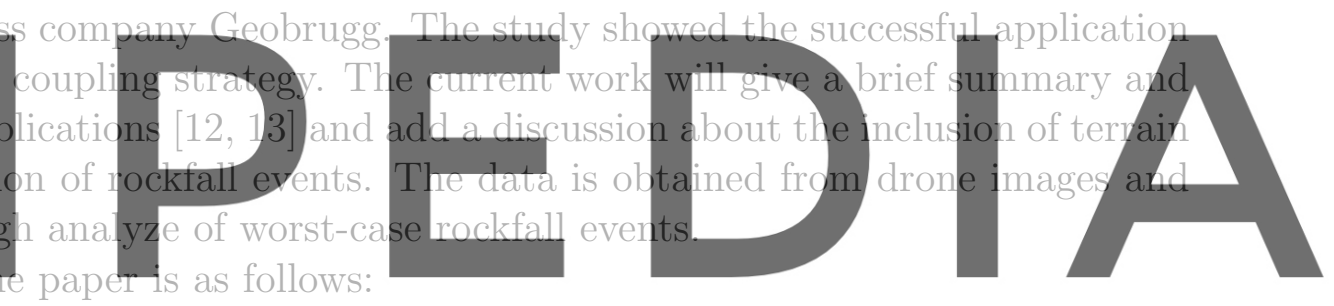

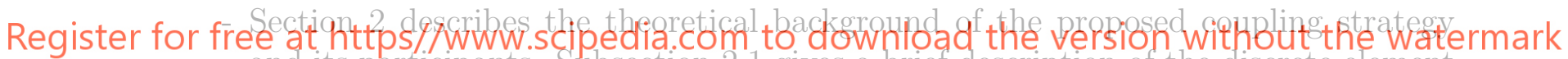
and its participants. Subsection 2.1 gives a brief description of the discrete element method. Subsequently, subsection 2.2 gives a brief description of the finite element method. Finally the partitioned coupling strategy and two different algorithms are presented in subsection 2.3.

- Section 3 discusses a rockfall impact experiment performed by the Swiss company Geobrugg and the results of the numerical simulation.

- Section 4 demonstrates the inclusion of terrain data in the workflow of the coupled simulation and discusses the advantages that come with it.

- Finally, Section 5 concludes this work with final words, a summary and an outlook to future research questions.

\section{COUPLING ENVIRONMENT}

As described by [13] the proposed coupling strategy utilizes the combination of two stand-alone numerical methods, namely the DEM and the FEM. While the DEM is used 
Klaus B. Sautter et al.

to model and simulate the motion of discrete objects and their interaction with boundaries discretized by surface, line, and vertex entities, the FEM is employed to analyze the respective structural response to the impact loads. The coupling of this co-simulation is realized in the open source multi-physics code $\operatorname{KRATOS}[6,7,8]$. The open-source character if this software is beneficial for the development of further improvements and the general availability to the public. In the following subsection the respective participants are briefly introduced and their coupling is explained. For more detailed explanations the reader is kindly redirected to $[10,13]$.

\subsection{DEM}

First described by [5] the DEM has been widely adopted to simulate the motion and interaction of discrete elements. It represents a particle method and thanks to its efficient handling of discrete elements it proofs to be suitable for the analysis of rockfall events [12]. Important investigations of the proper handling of impact/contact have been done by $[4$, $15,16]$.

The general workflow for a DEM simulation can be simplified to: Contact detection, analysis of contact forces, integration of motion, and subsequent advancement in time.

A detailed discussion of the single steps is out of the scope of this work, which is discussion of contact is heavily dependen spring-dashpot contact model was used (abbre algorithmic parameters

(damping coefficients in normal and tangential direction
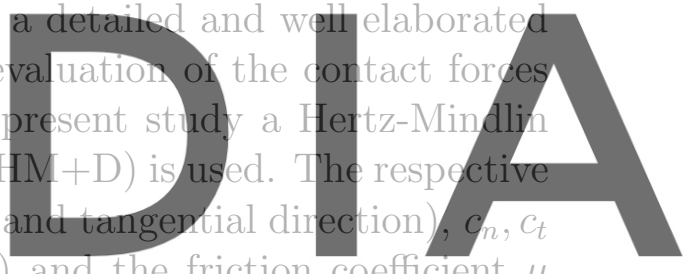

Register for free.at httos/\&www. Scipedia.com to download' the version withouthe watermark motion is pertormed based on Newton's second law ol motion. A variety of different time integration schemes can be used while this work employs a central-difference scheme [28]. Special care must be taken if the rotation needs to be properly integrated as described by $[9]$.

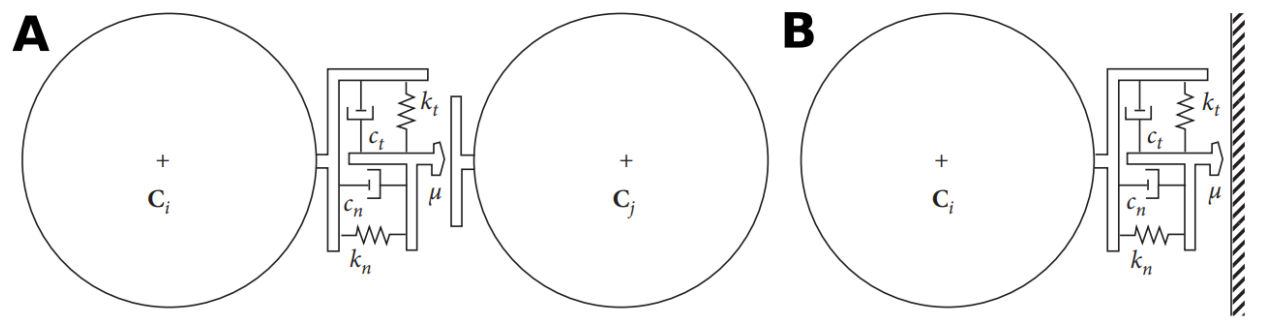

Figure 1: DEM-DEM and DEM-FEM rheological models. (A) DEM-DEM [10]. (B) DEM-FEM [10]. 
Klaus B. Sautter et al.

\section{$2.2 \quad$ FEM}

The FEM is used to analyze the structural response to the impact loads. With reference to a variety of interesting publications, among which we would like to emphasize [1], the virtual work,

$$
\delta W=\delta W_{i n t}+\delta W_{k i n}-\delta W_{e x t}=0,
$$

is calculated, including the internal $\delta W_{i n t}$, the kinetic $\delta W_{k i n}$, and the external $\delta W_{\text {ext }}$ virtual work. To solve for the equilibrium, Newton's type iterative schemes are applied, for which $\delta W$ has to be linearized. In order not to exceed the scope of this paper, we will not go into further detail in the following.

\subsection{PARTITIONED COUPLING}

With the DEM and the FEM at hand, the respective advantages can be used while bringing both methods together in a partitioned coupling simulation. The usage of FEM to model the structure allows the use of advanced element formulations like shell and membrane elements for the wire mesh [20], ring elements [24], and sliding cable formulations $[17,22]$. Both solvers are called successively and their respective solution data is exchanged. This procedure is schematically visualized in Figure 2.
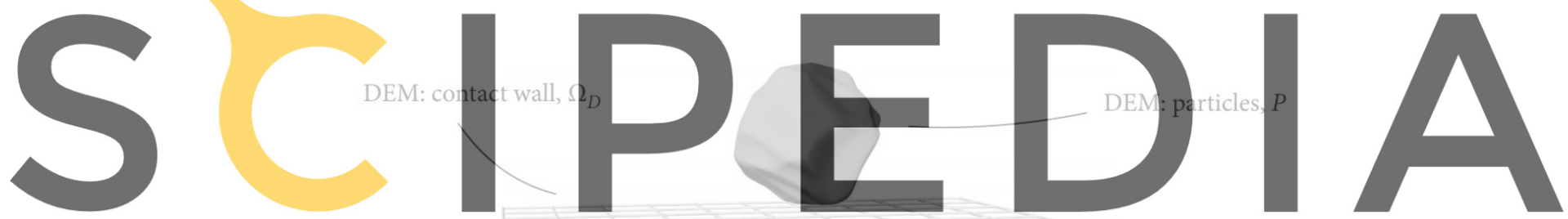

Register for free at https//wwww.scipedia.com to download the version without the watermark
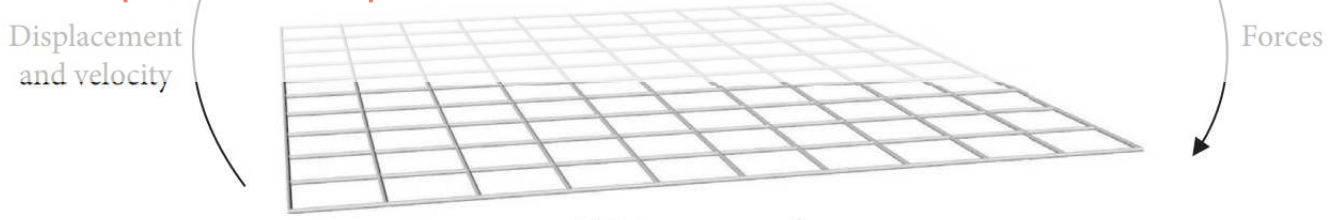

FEM: structure, $\Omega_{S}$

Figure 2: Transfer of forces and displacements and velocities at the interface, adapted from [13, 14].

The contact forces are calculated by the DEM and subsequently transferred to the FEM part. The structural response is then solved using the FEM and the state variables (displacement, and velocity) is transferred back to the DEM boundary. This procedure allows to use two standalone applications without the need to change any code in the respective solvers. To transfer the data a mapper is applied which handles the interface [29]. Depending on the problem setup two different coupling schemes can be applied and are summarized in a simplified form below [13]. 


\subsubsection{Weak Coupling}

As described in $[13,21,23]$ the weak coupling algorithm describes the direct exchange of data and a subsequent advancement in time and is depicted in Figure 3. This algorithm can easily become unstable if the contact forces or time steps become too large.

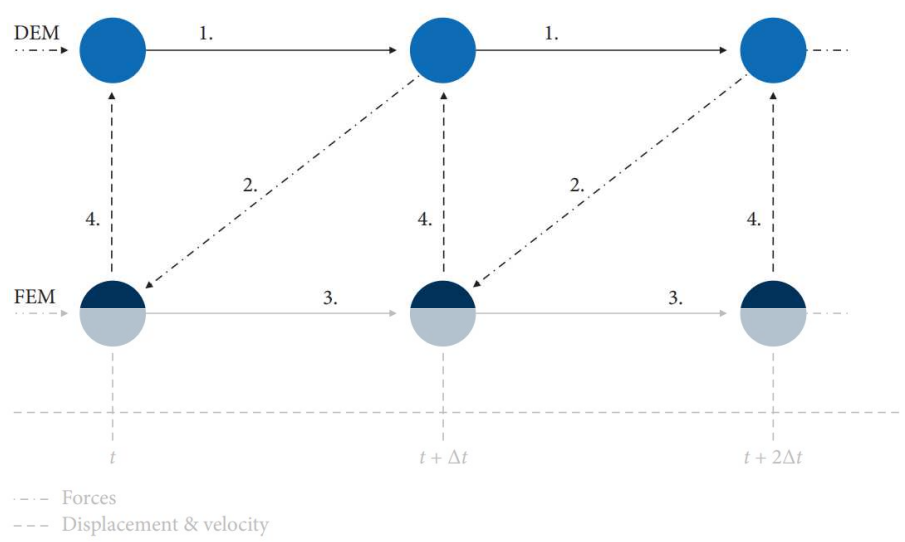

Figure 3: Staggered weak coupling procedure, between DEM and FEM, adapted from [13].
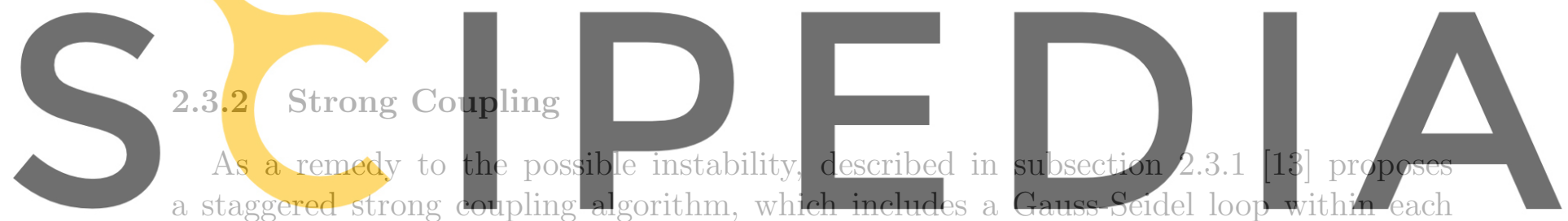

time step (see Figure 4). The data can be relaxed before being transferred with e.g. an

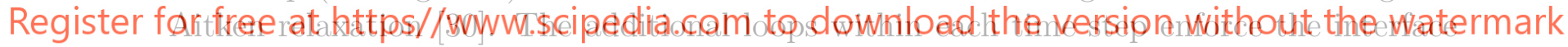
conditions [13] to be fulfilled with respect to an user defined interface residual.

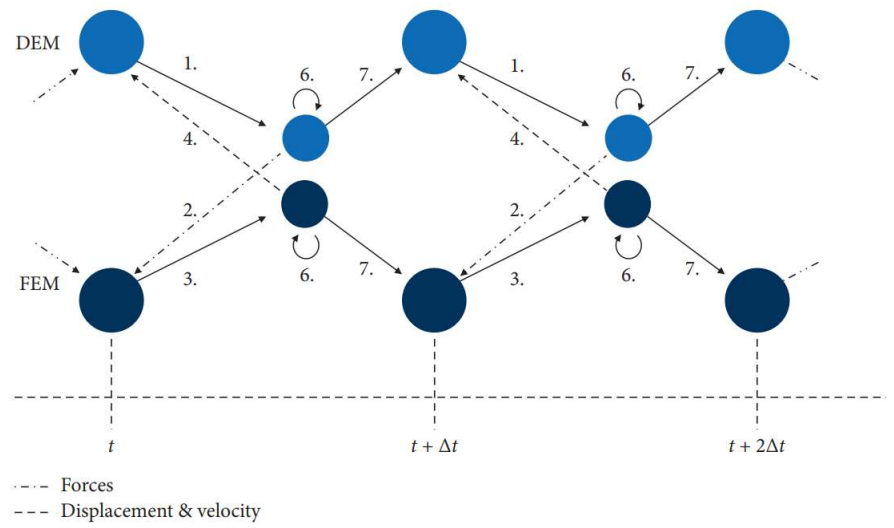

Figure 4: Staggered strong coupling procedure, between DEM and FEM, adapted from [13]. 


\section{Rockfall Experiment}

To proof the applicability of the proposed coupling strategy [12] simulated the rockfall impact on a test setup. The experiment was carried out in 2018 in Walenstadt, Switzerland, according to the Swiss guideline (SAEFL) by the company Geobrugg. A standardized concrete cube (mass: $180.0 \mathrm{~kg}$, edge length: $0.41 \mathrm{~m}$ ) was dropped from a height of $2.0 \mathrm{~m}$ on a wire mesh spanned between a test steel frame of $3.9 \times 3.9 \mathrm{~m}^{2}$, see Figure 5A,B. The experiment was repeated twice, ones for an initial sag due to dead load of $0.05 \mathrm{~m}$ (exp_1) and ones for $0.10 \mathrm{~m}$ (exp_2). The properties of the structural model were taken from laboratory tests and the unknowns were tuned to fit the initial sag of exp_1.

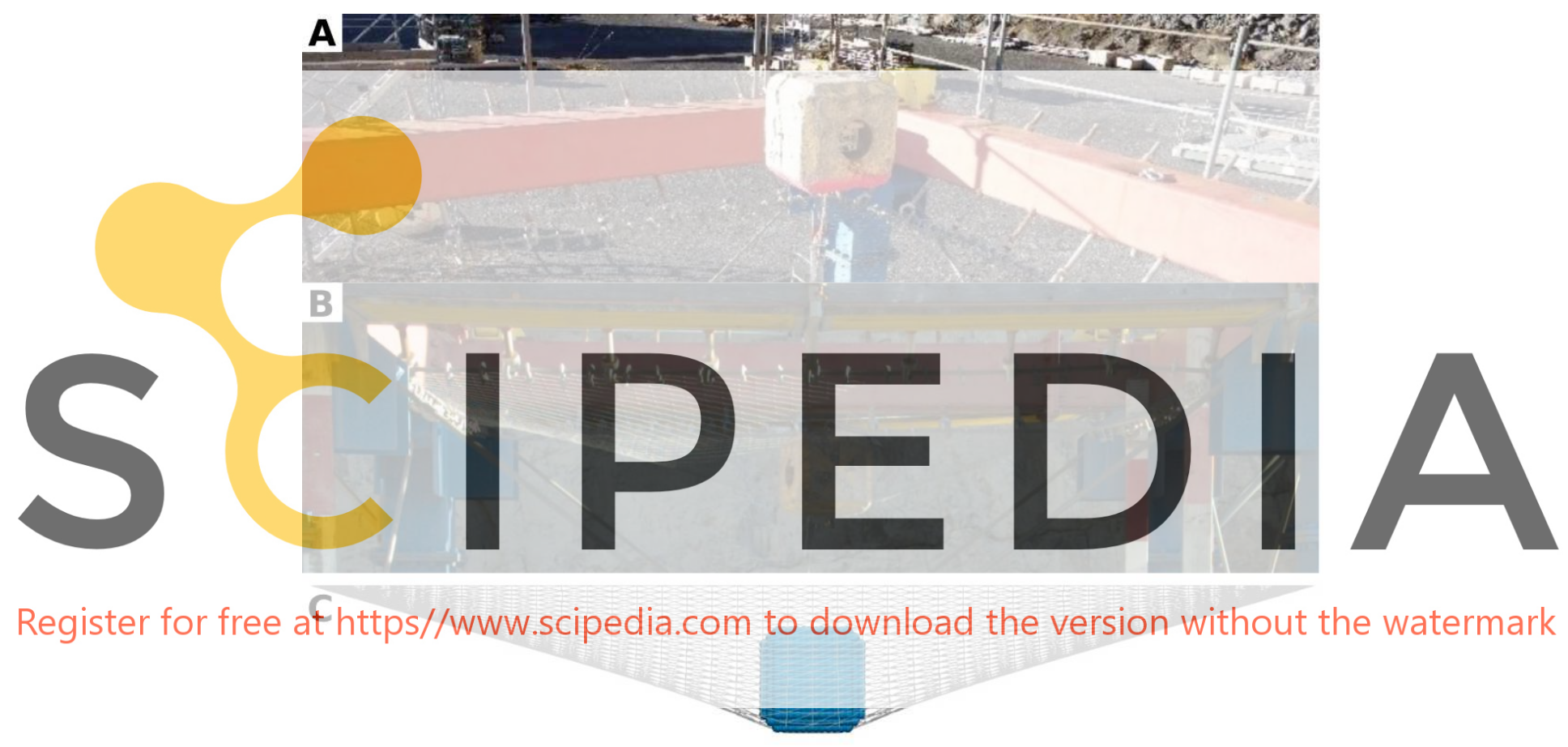

Figure 5: (A) Experimental set-up. (B) Experiment - deformation at maximum deflection. (C) Simulation - deformation at maximum deflection. Adapted from [12].

[12] models the impacting object as a cluster of spheres to approximate the real geometry while keeping the efficient contact algorithms for spheres. The clusters were created with the algorithms provided by $[2,3]$. For the simulation of the experiment the cluster refinement was varied from 1 sphere (c1) to 22,232 spheres (c7). The results of [12] are presented in Figure 6. Figure 6A visualizes the displacement, Figure 6B the velocity, and Figure $6 \mathrm{C}$ the reaction forces, measured in the support posts.

A general good agreement with the results of the experiments can be seen in Figures 6AC. The deviations for the single sphere are due to the poor distribution of the contact force. The detailed study and more information on this topic can be found in [13]. 
Klaus B. Sautter et al.
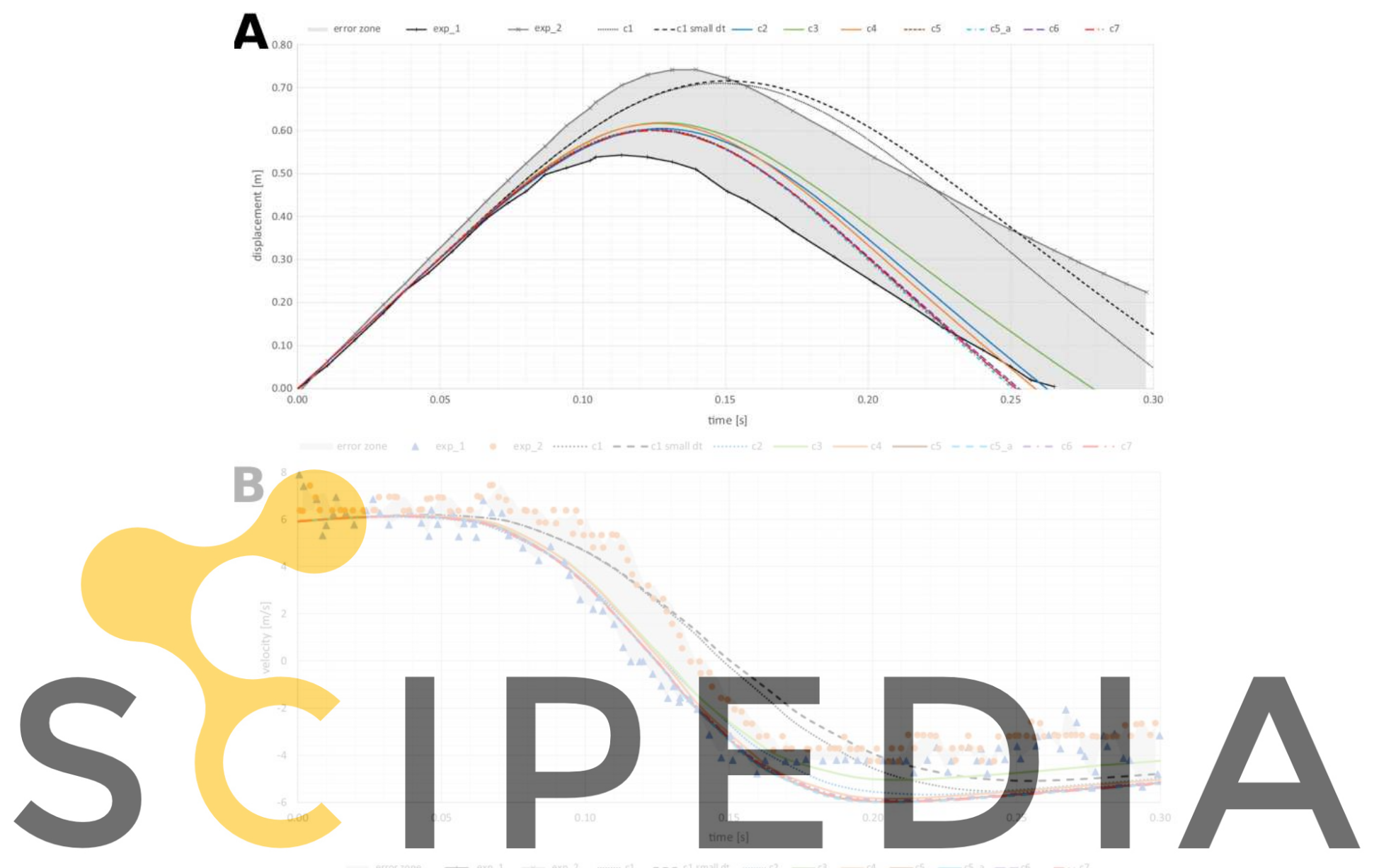

Register for free at https//www.scipedia.com to download the version without the watermark

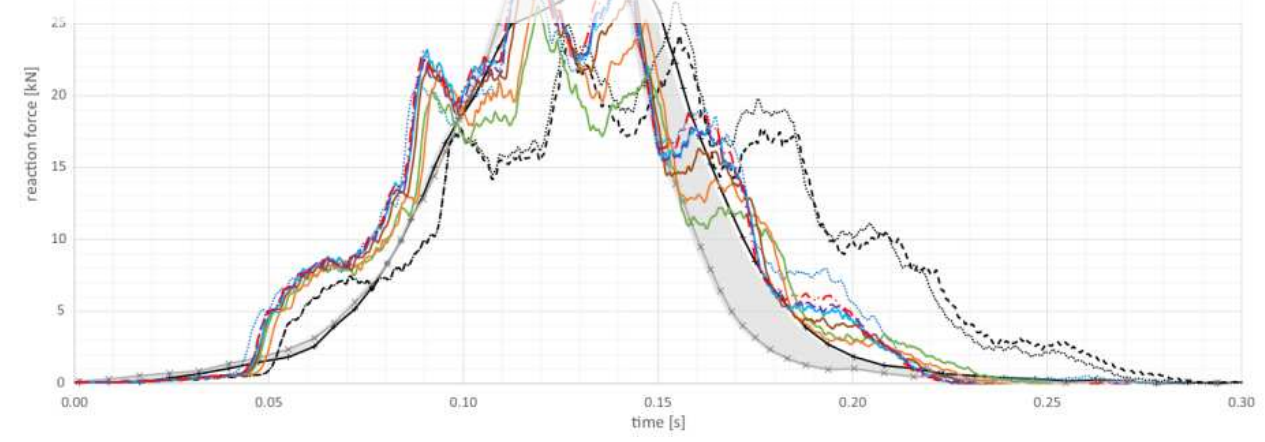

Figure 6: Simulation results for (A) Displacement, (B) Velocity, (C) Reaction forces. The study has been repeated for different levels of cluster refinement (c1-c7). All Figures are taken from [12].

\section{INCLUSION OF TERRAIN DATA}

The design of rockfall protection structures is highly dependent on the environmental conditions of the particular location and initial impact state, which, contrasting the 
numerically replicated experiment, is generally impossible to precisely know in advance. A practically flexible alternative is to incorporate site terrain data into the simulation and numerically predict the rockfall's path from its initial detachment until post-impact. The method of coupling DEM and FEM, which is used in this work, is robustly capable of incorporating virtual terrain models as a fixed triangulated boundary condition and in conjunction with the arbitrary rock description (via sphere clusters), facilitates the location-specific simulation of any rockfall event. In this way, the FEM model of the protective structure can be integrated very easily into the terrain model which, in the present example will be waived for clarity. The two rock shapes in Figure 7 are used to simulate a possible rockfall event, whereby the rock in Figure $7 \mathrm{C}$ is positioned so that it impacts with its edge. Both rocks are dropped from near the terrain surface with an initial velocity in gravity direction of $10 \mathrm{~m} / \mathrm{s}$ at the same place on the terrain slope, which is shown in Figure 8A. The trajectories of the rocks are illustrated in Figure 8B, which clearly shows the rocks intermittently contacting the terrain between accelerative freefall. Further simulations with several rock shapes would allow the user to analyze the worst case scenarios on the present slope.

A
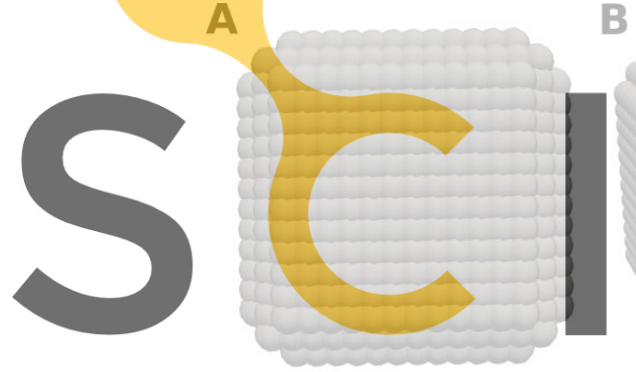

B
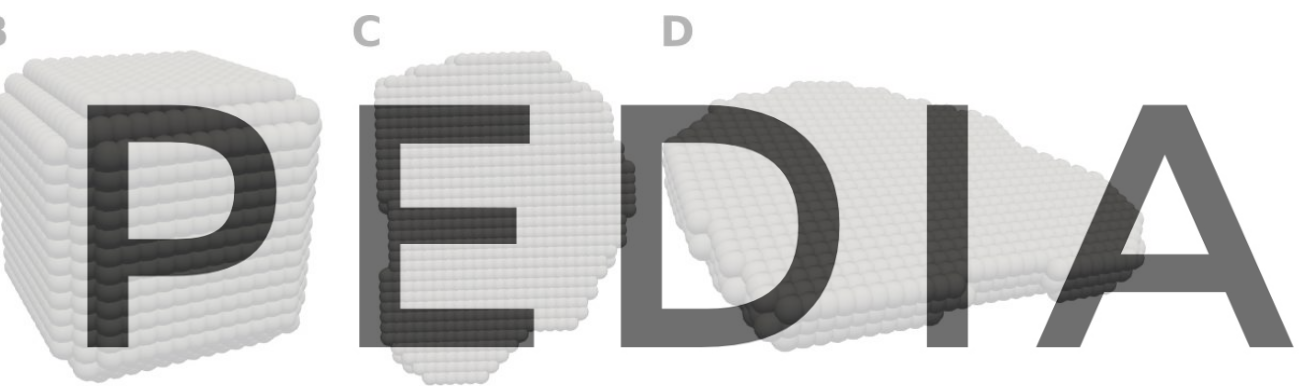

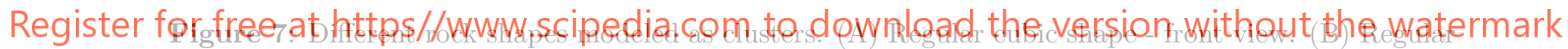
cubic shape - perspective view, (C) Arbitrary shape - front view. (D) Arbitrary shape - perspective view.

\section{CONCLUSIONS}

The simulation and analysis of rockfall impact on protection structures is a challenging and highly-nonlinear task. While a lot of design decisions are still based on field experiments the numerical analysis can be beneficial to get an efficient and cost-effective overview of the structural response to a given impact scenario. This work introduces and summarizes the recent advances by $[12,13]$. The proposed method couples two numerical methods, namely the DEM and the FEM to model and simulate the impact of rocks on flexible protection structures. Due to the large deformations which occur in the flexible protection structures the problem is highly nonlinear and needs a suitable method to realize a two-way coupled multi-physics simulation. This co-simulation is done in the open source multi-physics software KRATOS $[6,7,8]$ which allows the combination of multiple stand-alone applications. This study briefly explains the two algorithms for coupling the 
A

B

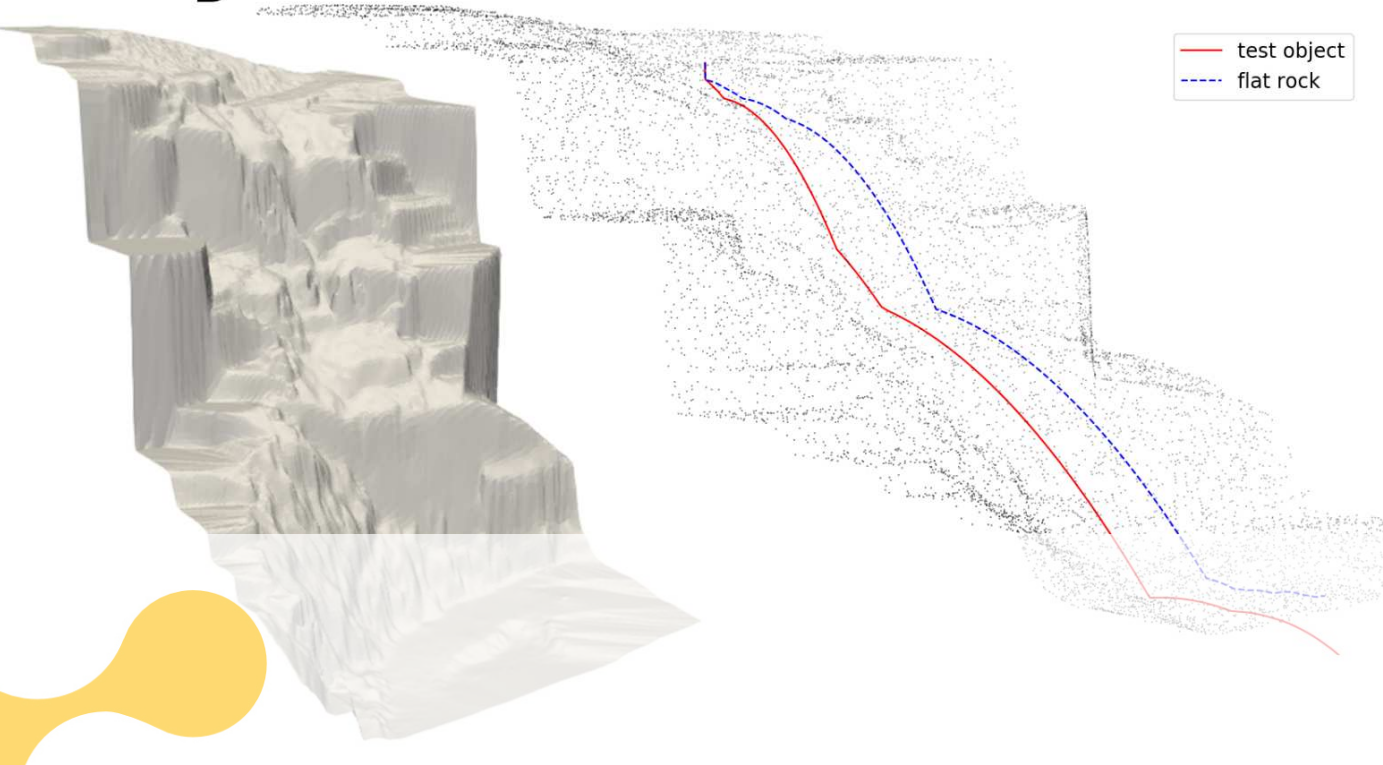

Figure 8: (A) Virtual terrain model as triangulated surface. (B) Trajectories of rockfall events including point-cloud of the terrain model. The red line represents the path of the rock visualized in Figures 7A,B, while the blue line shov
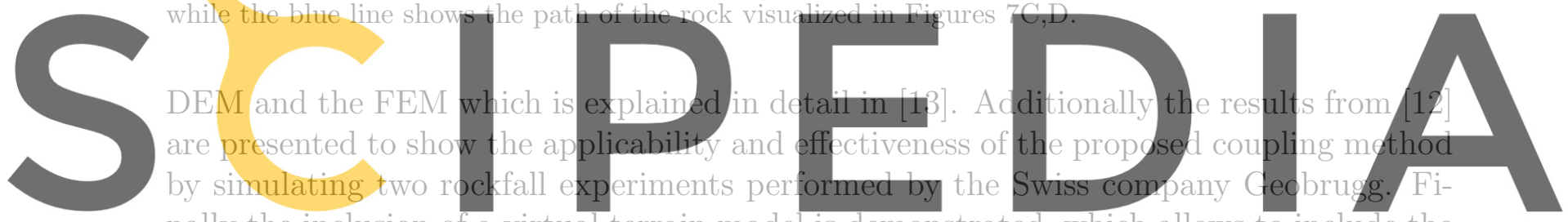

nally the inclusion of a virtual terrain model is demonstrated, which allows to include the

Register finflence of the surrounding: terrain into the rockfall simwation. This enaples the user te find the worst case scenarios for rock detachments and to find the most suitable position

for the installation of protection systems. Considered as a whole, the coupling environment in KRATOS, in conjunction with the developments and advances in the individual applications, thus provides an effective simulation environment for both analyzing the structural response to impacting rocks and taking into account the boundary conditions of the environment.

\section{REFERENCES}

[1] Belytschko, T., Kam, L. W., Moran, B., and Elkhodary, K. I. (2000). Nonlinear Finite Elements for Continua and Structures (New Haven: John Wiley \& Sons, Ltd)

[2] Bradshaw, G. and O'Sullivan, C. (2002). Sphere-Tree Construction using Dynamic Medial Axis Approximation. ACM Transactions on Graphics

[3] Bradshaw, G. and O'Sullivan, C. (2004). Adaptive Medial-Axis Approximation for Sphere-Tree Construction. ACM Transactions on Graphics 
[4] Cummins, S. J., Thornton, C., and Cleary, P. W. (2012). Contact Force Models in Inelastic Collisions. Ninth International Conference on CFD in the Minerals and Process Industries

[5] Cundall, P. A. and Strack, O. D. L. (1979). A discrete numerical model for granular assemblies. Gotechnique

[6] Dadvand, P., Rossi, R., and Oñate, E. (2010). An Object-oriented Environment for Developing Finite Element Codes for Multi-disciplinary Applications. Archives of Computational Methods in Engineering , 253297

[7] Dadvand, P., Rossi, R., Gil, M., Martorell, X., Cotela, J., Juanpere, E., et al. (2013). Migration of a generic multi-physics framework to HPC environments. Computers 86 Fluids, 301309

[8] Ferrándiz, V. M., Bucher, P., Rossi, R., Cotela, J., Carbonell, J., Zorrilla, R., et al. (2020). KratosMultiphysics (Version 8.0). Zenodo

[9] Irazábal, J., Salazar, F., Santasusana, M., and Oñate, E. (2019). Effect of the integration scheme on the rotation of non-spherical particles with the discrete element
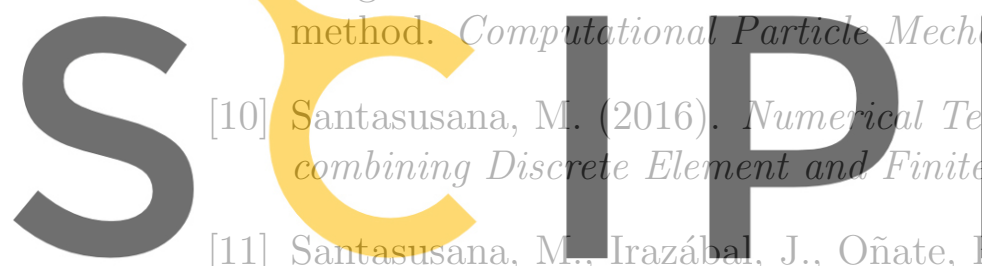

11] Santasusana, M., Irazálbal, J., Oñate,
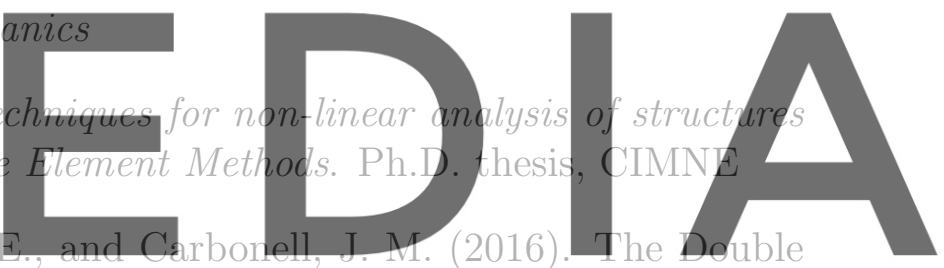

Hierarchy Method. A parallel 3D contact method for the interaction of spherical par-

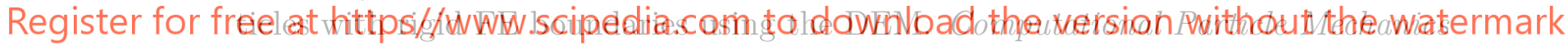

[12] Sautter, K. B., Hofmann, H., Wendeler, C., Wüchner, R., and Bletzinger, K.-U. (2021) Influence of DE-cluster refinement on numerical analysis of rockfall experiments. Computational Particle Mechanics

[13] Sautter, K. B., Teschemacher, T., Celigueta, M. A., Bucher, P., Bletzinger, K.-U., and Wüchner, R. (2020) Partitioned Strong Coupling of Discrete Elements with Large Deformation Structural Finite Elements to Model Impact on Highly Flexible Tension Structures. Advances in Civil Engineering: Advancements in the Analysis and Design of Protective Structures against Extreme Loadings

[14] Wendeler, C., Sautter, K. B., Bucher, P., Bletzinger, K.-U., and Wüchner, R. (2020) Modellierungsaspekte und gekoppelte DEM-FEM Simulationen zur Untersuchung hochflexibler Steinschlagschutznetze. Berichte der Fachtagung Baustatik Baupraxis 14 : 23. und 24. Mrz 2020, Universitt Stuttgart 
[15] Schwager, T. and Pöschel, T. (2007). Coefficient of restitution and linear-dashpot model revisited. Granular Matter

[16] Thornton, C., Cummins, S. J., and Cleary, P. W. (2012). An investigation of the comparative behaviour of alternative contact force models during inelastic collisions. Powder Technology

[17] Volkwein, A. (2004). Numerische Simulation von flexiblen Steinschlagschutzsystemen. Ph.D. thesis, ETH

[18] von Bötticher, A. (2012). Flexible Hangmurenbarrieren: Eine numerische Modellierung des Tragwerks, der Hangmure und der Fluid-Struktur-Interaktion. Ph.D. thesis, TUM

[19] Wendeler, C. (2008). Murgangrckhalt in Wildbchen - Grundlagen zu Planung und Berechnung von flexiblen Barrieren. Ph.D. thesis, ETH

[20] Tahmasbi, S., Giacomini, A., Wendeler, C., and Buzzi, O. (2019). On the Computational Efficiency of the Hybrid Approach in Numerical Simulation of Rockall Flexible Chain-Link Mesh. Rock Mechanics and Rock Engineering

[21] Winterstein, A., Lerch, C., Bletzinger, K.-U., and Wchner, R. (2018). Partitioned simulation strategies for fluidstructurecontrol interaction problems by GaussSeidel formulations. Advanced Modeling and Simulation in Engineering Sciences

[22] Boulaud, R. and Douthe, C. (2017). A Sliding Cable Model for Rockfall Barrier Simulations Using Dynamic Relaxation. IASS Annual Symposium

[23] Wüchner, R. (2006). Computational Mechanics of formfinding and fluid-structure interaction of membrane structures. Ph.D. thesis, TUM

[24] Escallon, J. P., Boetticher, V., Wendeler, C., Chatzi, E., and Bartelt, P. (2015). Mechanics of chain-link wire nets with loose connections. Engineering Structures

[25] Mentani, A., Govoni, L., Giacomini, A., Gottardi, G., and Buzzi, O. (2018). An Equivalent Continuum Approach to Efficiently Model the Response of Steel Wire Meshes to Rockfall Impacts. Rock Mechanics and Rock Engineering

[26] Dhakhal, S., Bhandary, N., Yatabe, R., and Kinoshita, R. (2011). Experimental, numerical and analytical modelling of a newly developed rockfall protective cablenet structure. Natural Hazards and Earth System Sciences

[27] Sasiharan, N., Muhunthan, B., Badger, T., Shu, S., and Carradine, D. M. (2006). Numerical analysis of the performance of wire mesh and cable net rockfall protection systems. Engineering Geology 
[28] Matuttis, H.-G. and Chen, J. (2014). Understanding the Discrete Element Method: Simulation of Non-Spherical Particles for Granular and Multi-Body Systems (Wiley)

[29] Tianyang, W. (2016). Development of Co-Simulation Environment and Mapping Algorithms. Ph.D. thesis, TUM

[30] Aitken C. (1927). XXV.on Bernoullis numerical solution of algebraic equations Proceedings of the Royal Society of Edinburgh, Edinburgh, UK. 